\title{
Limited pollen dispersal and biparental inbreeding in Symphonia globulifera in French Guiana
}

\author{
B Degen ${ }^{1,2}$, E Bandou ${ }^{1}$ and H Caron ${ }^{3}$ \\ ${ }^{1}$ INRA, Campus agronomique, BP 709, 9738 - Kourou cedex, French Guiana; ${ }^{2}$ BFH, Institute for Forest Genetics and Forest Tree \\ Breeding, Sieker Landstrasse 2, D-22927 Grosshansdorf, Germany; ${ }^{3}$ INRA, Laboratoire de genetique et d'amelioration des arbres \\ forestiers, 69 route d'Arcachon, 33612 Cestas Cedex, France
}

\begin{abstract}
In this paper, we report a study of the mating system and gene flow of Symphonia globulifera, a hermaphroditic, mainly birdpollinated tree species with a large geographic distribution in the tropical Americas and Africa. Using three microsatellites, we analysed 534 seeds of 28 open pollinated families and 164 adults at the experimental site 'Paracou' in French Guiana. We observed, compared to other tropical tree species, relatively high values for the effective number of alleles. Significant spatial genetic structure was detected, with trees at distances up to $150 \mathrm{~m}$ more genetically similar than expected at random. We estimated parameters of the mating system and gene flow by using the mixed mating model and the TwoGener approach. The estimated multilocus outcrossing
\end{abstract}

rate, $t_{\mathrm{m}}$, was 0.920 . A significant level of biparental inbreeding and a high proportion of full-sibs were estimated for the 28 seed arrays. We estimated mean pollen dispersal distances between 27 and $53 \mathrm{~m}$ according to the dispersal models used. Although the adult population density of $S$. globulifera in Paracou was relatively high, the joint estimation of pollen dispersal and density of reproductive trees gave effective density estimates of 1.6 and 1.3 trees/ha. The parameters of the mating system and gene flow are discussed in the context of spatial genetic and demographic structures, flowering phenology and pollinator composition and behaviour.

Heredity (2004) 93, 585-591. doi:10.1038/sj.hdy.6800560 Published online 18 August 2004

Keywords: gene flow; microsatellites; mixed mating; spatial autocorrelation; tropical tree; twogener

\section{Introduction}

For management and conservation of tree populations, it is important to know the distances of effective pollen dispersal and the mating system as a function of tree density (Sork et al, 2002). The managers of tropical forests need to know critical limits for remnant tree densities in order to plan selective logging in a way that avoids reproductive isolation (Kanashiro et al, 2002), which may result in reduced seed production, lower genetic variation and increased inbreeding depression (Obayashi et al, 2002). In areas with forest fragmentation, studies on pollen and seed dispersal distances provide essential information on the level of isolation of remaining forest fragments (Aldrich and Hamrick, 1998; Dick, 2001).

Recently, highly variable microsatellites have been employed to study the gene flow and mating system of tropical trees (Collevatti et al, 2001; Dick, 2001; White et al, 2002). These studies revealed unexpectedly long pollen flow distances and the impact of pollinator community on pollen dispersal. In most cases, the tree species being studied occurred naturally at low density. Dick et al (2003) measured, for the insect-pollinated tropical tree Dinizia excelsa with a density of 0.3 trees/ha (dbh $\geq 10 \mathrm{~cm}$ ), a mean pollen dispersal of $212 \mathrm{~m}$ in undisturbed forests and mean pollen dispersal of $1509 \mathrm{~m}$ in a

Correspondence: B Degen, BFH, Institute for Forest Genetics and Forest Tree Breeding, Sieker Landstrasse 2, D-22927 Grosshansdorf, Germany. E-mail: b.degen@holz.uni-hamburg.de

Received 6 November 2004; accepted 22 June 2004; published online 18 August 2004 fragmented forest with much lower density. There is evidence for a negative relationship between the level of selfing and the density of reproductive trees (Murawski and Hamrick, 1991). The mating system and gene dispersal of tropical trees have been proven to be highly dynamic and sensitive to ecological factors (Franceschinelli and Bawa, 2000). The level of outcrossing and the distribution of effective pollen might change from one flowering event to another and from one population to another simply as a function of demographic structure, phenology and pollinator composition and abundance. Hence, even in undisturbed forests we have a 'natural' variation on these parameters.

We need to know the range of this natural variation before we can analyse the impact of forest exploitation and fragmentation on the mating system and the gene flow. The evolution of tropical trees species seems to have favoured characteristics in the reproductive system, such as specialized animal pollination, that allow them to persist at low densities. Hence, tropical rainforest trees might, to some extent, tolerate an additional local reduction of their density due to forest exploitation. It is further possible that typically abundant species may be more sensitive to reduction in densities than rare species because they are less adapted to this situation.

Symphonia globulifera L. f. (Clusiaceae) is an interesting species from this point of view. This hermaphroditic species has an exceptionally large geographic distribution from Mexico south to Rio de Janeiro and it is also present in the tropical West Africa. Dick et al (2003) studied the phylogeographic history of S. globulifera over this broad geographic range. Their results indicated the 
colonisation of Central and South-America through marine dispersal from Africa during the mid Miocene (ca. 15 million years ago). The density of S. globulifera is extremely variable among populations. Counting trees with diameter at breast height (d.b.h.) $\geq 10 \mathrm{~cm}$, densities of $122 \mathrm{~N} /$ ha (Quakal swamp forest) and $65 \mathrm{~N} / \mathrm{ha}$ (Manicole swamp forest) have been reported in Guyana (Andel, 2003). At the other extreme, the population of $S$. globulifera on Barro Colorado Island (Panama) has a density of only 0.5 trees/ha (Center for Tropical Forest Sciences, 2000 forest census). There are also contrasting reports on the community of pollinators of $S$. globulifera at different places. In Costa Rica, Pascarella (1992) observed Lepidoptera as the most important pollinators, in central French Guiana Gill et al (1998) identified perching birds as the principal pollinators, whereas Bittrich and Amaral (1996) and Maues (2001) suggested hummingbirds as the pollinators in the Central Amazon. Another advantage of selecting S. globulifera as a study subject is the availability of microsatellite markers and additional population genetic data for comparison (Aldrich et al, 1998).

In this paper, we report a study of the gene flow and mating system of $S$. globulifera at the experimental site 'Paracou' in French Guiana. This site is characterised by a relatively high density of this species. We will focus on the following questions: Do we also find long distance pollen dispersal for this abundant tropical tree species? Do we observe a spatial genetic autocorrelation in the adult population and, if yes, does it fit to expectations given by the measured gene flow and mating system? Is the mating system of high-density animal-pollinated tree species different from observations of low-density species? The answers to these questions will help to address whether abundant species are more sensitive to logging operations than rare species.

\section{Material and methods}

\section{Site and sampling}

The experimental trial 'Paracou' $\left(5^{\circ} 18^{\prime} \mathrm{N}, 52^{\circ} 53^{\prime} \mathrm{W}\right)$ is located in French Guiana near Sinnamary. The forest of Paracou is classified as lowland moist forest on ferralitic soil. The mean annual rainfall in this area is $3.076 \mathrm{~mm}$, with peaks in April-June and December. There are two dry seasons; a long one from August to November and a shorter one in March. The experimental trial consists of 16 plots: 15 are 6.25 ha in size and one covers an area of 25 ha. Since 1984, all trees with a d.b.h. $\geq 10 \mathrm{~cm}$ have been measured by CIRAD Forêt. The trees have been mapped and most species have been identified. On the total surface area of $118.7 \mathrm{ha}, 1295$ trees of S. globulifera with a d.b.h. $\geq 10 \mathrm{~cm}$ have been identified (10.9 trees/ha). Three silvicultural treatments of different intensities were applied to different plots from 1986 to 1988 but some were left as unlogged controls. After 15 years, the effect of the treatments on the density on S. globulifera is quite low. There is even a slightly higher density of $S$. globulifera in the logged plots (12.6 trees/ha) compared to the control plots (10.5 trees/ha). A detailed description of the experimental trial and treatments can be found elsewhere (Schmitt and Bariteau, 1988; Forget et al, 1999).

For the genetic study, we collected cambium from 164 trees. This included 147 trees from plot 16
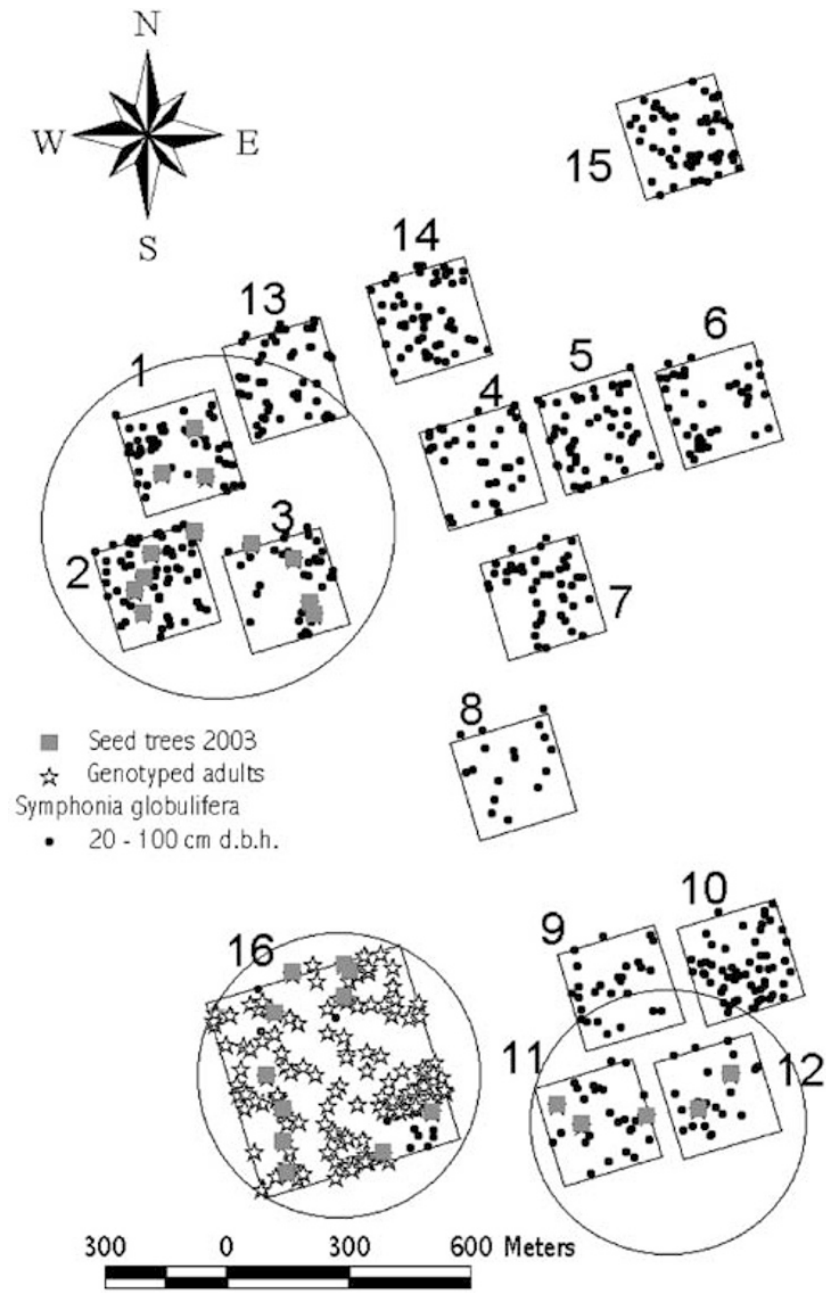

Figure 1 Distribution of S. globulifera with d.b.h. $\geq 20 \mathrm{~cm}$ in Paracou. Most of the trees sampled for genotyping were located in plot 16 (stars). We sampled 560 seeds from 28 mother trees (squares) in three different parts of Paracou (circles).

$\left(500 \times 500 \mathrm{~m}^{2}\right)$ and the 17 sampled seed trees outside plot 16. In February 2003, we collected 560 seeds from 28 mother trees (20 seed each) distributed in three clusters over the experimental site (see Figure 1). The reason of this design was to sample at different spatial scales, because we had no a priori information whether the average pollination distance would be in the 30 or $500 \mathrm{~m}$ range (Sork et al, 2002).

\section{Microsatellites}

For adult trees, a disc of $150 \mathrm{mg}$ of cambium stored in a conservation buffer made of $70 \%$ ethanol and $0.3 \% \beta$ mercaptoethanol was used for DNA extractions. The buffer-preserved discs were flash- frozen in liquid Nitrogen and then ground to a powder using a mortar and pestle. Subsequent DNA extraction followed modifications of the widely used CTAB extraction procedure (Doyle and Doyle, 1987) $(2 \times$ CTAB buffer: $100 \mathrm{mM}$ Trisma base, $1.4 \mathrm{mM} \mathrm{NaCl}, 20 \mathrm{mM}$ ethylenediaminetetra-acetic acid (EDTA), 2\% Cetyltrimethylammonium bromide (CTAB), 1-4\% polyvinylpyrrolidone (PVP)-40, $0.2 \%$ ascorbic acid, $\beta$-mercaptoethanol $0.3 \%$ ). Total 
genomic DNA was extracted from seed tissues following the same protocol.

Genotypes were scored at three microsatellite loci. One primer pair SgC4 was adopted from Aldrich et al (1998). Two additional primer pairs were developed (Sg03 and Sg18) during this study. The clone sequence of $\mathrm{Sg03}$ contained the compound repeat $(\mathrm{CT})^{19}$ and the size range of the nucleotides after polymerase chain reaction (PCR) was 302-354 base pairs (bp). The Sg18 clone contained the repeat $(\mathrm{CT})^{24}$ and the alleles ranged in size from 229 to $333 \mathrm{bp}$. The primer sequences were as follows: Sg03, forward 5'TCTATCTGCCAAGTGAGACA, Sg03 reverse 5'GAACATTTTTTTGGTGGGAC; Sg18, forward 5'TCTTTTGCCTTTTTAGTTGA, Sg18 reverse TGAGGATTGTTTGCCCAGAA.

The PCR cocktail $(20.0 \mu \mathrm{l}$ total) contained $0.05 \mu \mathrm{M}$ of each $\mathrm{dNTP}, 0.012 \mu \mathrm{M}$ of $\mathrm{MgCl}_{2}, 1 \mathrm{U}$ of Taq polymerase (Invitrogen Corporation), $0.002 \mu \mathrm{M}$ of each primer and $0.2 \mathrm{ng}$ of DNA. The PCR was performed on an ABI 9700 thermal cycler using the following protocol: $5 \mathrm{~min}$ at $94^{\circ} \mathrm{C}$; 30 cycles of $45 \mathrm{~s}$ at $94^{\circ} \mathrm{C}, 45 \mathrm{~s}$ at $55^{\circ} \mathrm{C}$ and $45 \mathrm{~s}$ at $72^{\circ} \mathrm{C}$; ending with $5 \mathrm{~min}$ at $72^{\circ} \mathrm{C}$. The amplification products were visualised by electrophoresis with a LIZ500 size standard (Applied Biosystems Incorporated, $\mathrm{ABI}$ ) on an ABI 310 automated sequencer. Allele sizes were scored using the program Genotyper from Applied Biosystems. The observed segregation within families showed codominant inheritance of the microsatellite fragments.

\section{Data analysis}

Genetic variation and heterozygosity: For each locus, the number of different alleles $(A)$, observed heterozygosity $\left(H_{\mathrm{o}}\right)$, expected heterozygosity $\left(H_{\mathrm{e}}\right)$, the effective number of alleles $A_{\mathrm{e}}=1 /\left(1-H_{\mathrm{e}}\right)$ and the Fixation index $F=1-\left(H_{\mathrm{o}} / H_{\mathrm{e}}\right)$ were calculated as described by Weir (1996). To estimate the significance of $F$, numerical tests were performed on the basis of Monte-Carlo methods (Manly, 1997). A total of 1000 permutations of homologous alleles among individuals were run to test the significance of the $F$-values for each locus. Each permutation leads to a new random association of the alleles within the sample of seeds and adults (resampling without replacement). After each permutation, the $F$-values were recalculated and compared to the observed values. The relative frequency of those cases leading to more extreme $F$ values than the observed values were used to estimate the probability of significant deviation from the HardyWeinberg proportions.

Spatial genetic structure: Moran's Index $I_{q}$ was computed with the program SGS (Degen et al, 2001b) for multilocus genotypes of the adults (Sokal and Oden, 1978a). The index is calculated for a given distance class $s_{q}$. For each allele having higher frequency than the threshold of $2 \%$ in all samples, $I_{q}$ was calculated as follows:

$$
I_{q}=\frac{n \sum_{i=1}^{n} \sum_{j \neq i}^{n} w_{i j}\left(a_{i}-\bar{a}\right)\left(a_{j}-\bar{a}\right)}{W \sum_{i=1}^{n}\left(a_{i}-\bar{a}\right)^{2}} \quad W=\sum_{i=1}^{n} \sum_{j \neq i}^{n} w_{i j}
$$

$n$ is the total number of samples and $w_{i j}=1$ if the individuals $i$ and $j$ belong both to the spatial interval $s_{q}$, otherwise $w_{i j}=0$. For diploid data, $a_{i}$ is 1 if the $i$ th individual is homozygous for that allele, 0.5 if heterozygous, and 0 if the individual has no copy of the allele. The value $\bar{a}$ corresponds to the mean value of $a_{i}$ over all $n$ individuals. Following Streiff et al (1998), autocorrelation is calculated over all selected loci summing the numerator and denominator of the first equation over the total number of alleles. The expected values for the case of no autocorrelation are $-1 /(n-1)$ (Sokal and Wartenberg, 1983). Higher values indicate positive spatial autocorrelation and smaller values indicate negative spatial autocorrelation.

A permutation procedure using Monte-Carlo simulations was applied to test significant deviation from random spatial distribution of each $I_{q}$-value. Each permutation consisted of a random redistribution of the microsatellite genotypes over the spatial coordinates of the sampled trees. For each of the spatial distance classes $s_{q}$, observed values were compared with the distribution obtained after 1000 permutations. A 95\% confidence interval for the parameters was constructed as the interval from the 25th to the 975th ordered permutation estimates (Streiff et al, 1998).

Mating system: By use of the mixed mating model (Ritland and Jain, 1981), we estimated the single- and multilocus outcrossing rates. The outcrossing rates were calculated with the program MLTR version 2.3 (Ritland, 2002) by maximum likelihood, fitting the observed proportions of genotypes descended from a known maternal genotype to the proportions expected under the mixed mating model. The model assumes that: (a) each mating represents a random event of an outcross or a self-fertilization, with probabilities equal to $t$ and $(1-t)$, respectively; (b) no selection and no mutation following fertilization may occur; (3) there is no assortative mating or variability in pollen pool frequencies (Ritland and Jain, 1981). With version 2.3 of MLTR (Ritland, 2002) some departures from these assumptions could be accommodated and be treated as additional facets of the mating system. If mating occurs between relatives (biparental inbreeding), the single-locus selfing rate $\left(s_{\mathrm{s}}\right)$ should be higher than the multilocus selfing rate $\left(s_{\mathrm{m}}\right)$, and the difference provides a minimum estimate of the apparent selfing due to biparental inbreeding. The reason for this expected difference between $s_{\mathrm{s}}$ and $s_{\mathrm{m}}$ is that the more loci used, the lower the likelihood of confusing selfed and biparentally inbred progeny (Griffin and Eckert, 2003). In addition, we calculated the correlation of outcrossed paternity within progeny arrays $\left(r_{\mathrm{p}}\right)$, which is the probability that a randomly chosen pair of seeds from the same family are full-sibs. We performed 500 bootstraps over families to get standard errors for each parameter.

TwoGener: Following Smouse et al (2001) we made a twogener analysis on the progeny arrays of Paracou. The principle of this method is to estimate $\Phi_{\mathrm{FT}}$, the differentiation of allelic frequencies among the pollen pools sampled by several mother trees in the population. The relation between $\Phi_{\mathrm{FT}}$ and dispersal distance has been shown for given dispersal curves (Austerlitz and Smouse, 2001), allowing the development of several estimates of pollen dispersal (Austerlitz and Smouse, 2002; Austerlitz et al, 2004). A general estimate is based on the global $\Phi_{\mathrm{FT}}$ measured on all the seed trees of the 
Table 1 Sample size $(N)$, number of alleles $(A)$, effective number of alleles $\left(A_{\mathrm{e}}\right)$, observed and expected frequencies of heterozygotes $\left(H_{\mathrm{o}}, H_{\mathrm{e}}\right)$, Fixation index $(F)$ and probability for departure from Hardy-Weinberg Heterozygosity $(P)$ for adults and seeds in Paracou

\begin{tabular}{|c|c|c|c|c|c|c|c|c|c|c|c|c|}
\hline \multirow[t]{2}{*}{ Locus } & \multicolumn{6}{|c|}{ Adults $(\mathrm{N}=164)$} & \multicolumn{6}{|c|}{ Seeds $(\mathrm{N}=534)$} \\
\hline & A & $\mathrm{A}_{e}$ & $\mathrm{H}_{o}$ & $\mathrm{H}_{e}$ & $\mathrm{~F}$ & $\mathrm{P}$ & A & $\mathrm{A}_{e}$ & $\mathrm{H}_{o}$ & $\mathrm{H}_{e}$ & $\mathrm{~F}$ & $\mathrm{P}$ \\
\hline $\mathrm{Sg} 03$ & 26 & 9.38 & 0.59 & 0.89 & 0.33 & 0.000 & 20 & 8.46 & 0.70 & 0.88 & 0.20 & 0.000 \\
\hline $\mathrm{SgC4}$ & 30 & 14.52 & 0.93 & 0.93 & 0.00 & 0.500 & 26 & 14.02 & 0.90 & 0.92 & 0.02 & 0.026 \\
\hline Sg18 & 13 & 5.03 & 0.66 & 0.80 & 0.17 & 0.000 & 17 & 7.25 & 0.74 & 0.86 & 0.13 & 0.000 \\
\hline Mean & 24 & 8.02 & 0.73 & 0.87 & 0.16 & 0.000 & 21 & 9.16 & 0.78 & 0.89 & 0.12 & 0.000 \\
\hline
\end{tabular}

population. This provides an estimate of the pollen dispersal distance (delta) assuming a given dispersal curve and a density of reproducing adults $(d)$ in the landscape. We tested the normal and exponential dispersal functions and used, according to former phenological observations, a proportion of the known adult density as entry into the estimation. Also, the pairwise $\Phi_{\mathrm{FT}}$ between all mother trees in the population were calculated to design pairwise estimates that allow one to jointly infer the parameters pollen dispersal distance (delta) and a density of reproducing adults (d). As noted by Austerlitz and Smouse (2002), the pairwise analysis yields more accurate estimates of $\Phi_{\mathrm{FT}}$ but requires larger sample sizes. We computed the $99 \%$ confidence interval of $\Phi_{\mathrm{FT}}$ by bootstrapping among loci with 1000 replicates (Weir, 1996).

\section{Results}

\section{Genetic variation and heterozygosity}

The genetic variation measured by the mean number of alleles was, despite a lower sample size, higher for the adults compared to the seeds (adults: $A=24$; seeds: $A=21$, Table 1 ). However, the alleles were more evenly distributed in the seeds, as shown by the higher mean values of the effective number of alleles $\left(A_{\mathrm{e}}\right)$. Both ontogenetic stages had a highly significant excess of homozygotes (mean adults: $F=0.16$; mean seeds: $F=0.12$ ). For both samples, there was a high variation of the $F$-values among loci with a strong excess of homozygotes for loci Sg03 and Sg18 and nearly HardyWeinberg proportions for locus SgC4.

\section{Spatial genetic structure}

The shape of the correlogram showed a general pattern of decreasing spatial autocorrelation among trees with increasing spatial distances (Figure 2). The mean value of the Moran's I among adult trees at distances of up to $150 \mathrm{~m}$ was significantly higher, and the value among trees at distances of $300-500 \mathrm{~m}$ was significantly lower than expected for a random spatial genetic structure. The values varied between +0.041 and -0.031 indicating only a weak spatial genetic structure.

\section{Mating system}

The multilocus outcrossing rate $\left(t_{\mathrm{m}}\right)$ had a value of 0.92 (0.017). There was a significant difference between the multilocus and single-locus estimates $t_{\mathrm{m}}-t_{\mathrm{s}}=0.156$ (0.022). This implies a relatively high proportion of biparental inbreeding in Paracou. Another striking result

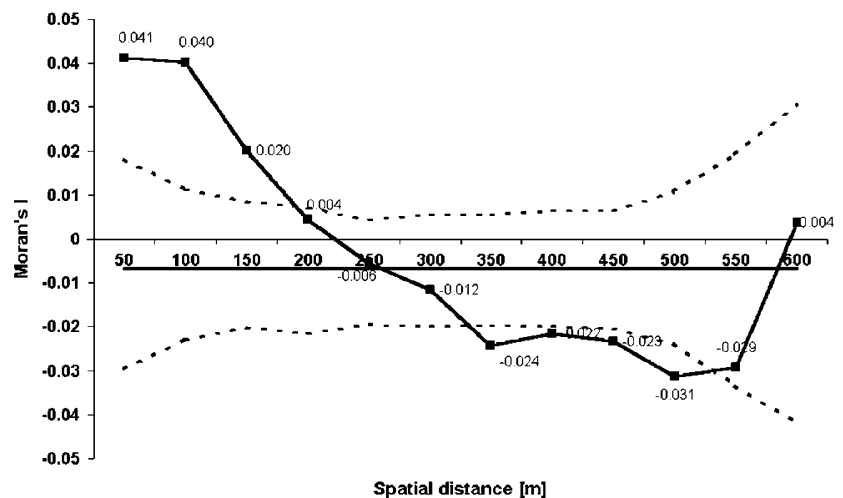

Figure 2 Mean Moran's Index among trees in different spatial distance classes (line with squares), 95\% confidence interval as drawn from 1000 permutations (dotted line) and expected Moran's Index for absence of spatial genetic structure (black central line).

Table 2 Density of reproductive trees and mean pollen dispersal distance (delta) estimated for the normal and exponential dispersal model. The error is a quadratic criterion for the fit between expected and observed values for pairwise $\Phi_{i j}$ estimates (Austerlitz and Smouse, 2002)

\begin{tabular}{llccc}
\hline $\begin{array}{l}\text { Dispersal } \\
\text { function }\end{array}$ & $\begin{array}{l}\text { Density } \\
\text { constraint }\end{array}$ & $\begin{array}{c}\text { Density of } \\
\text { reproductive } \\
\text { trees }(\mathrm{N} / \mathrm{ha})\end{array}$ & Delta $(\mathrm{m})$ & Error \\
\hline Normal & Fixed & 4.0 & 27.4 & 1.70 \\
Normal & Estimated & 1.6 & 42.9 & 1.69 \\
Exponential & Fixed & 4.0 & 30.9 & 1.69 \\
Exponential & Estimated & 1.3 & 53.1 & 1.68 \\
\hline
\end{tabular}

was the significant high value for the correlation of outcrossed paternity $r_{\mathrm{p}}=0.47$ (0.059). Hence, the number of effective pollen donors in a family was very limited, despite a relatively high density of trees in Paracou.

\section{Gene flow}

The distance between sampled seed trees varied between 45 and $2010 \mathrm{~m}$ with a mean of $955 \mathrm{~m}$. The differentiation of allelic frequencies among the pollen pools was $\Phi_{\mathrm{FT}}=0.205$ with the $99 \%$ confidence interval from 0.147 to 0.288 . The estimates of the mean pollen dispersal (delta) for the normal model were $27.4 \mathrm{~m}$ with fixed tree density and $42.9 \mathrm{~m}$ for the joint estimation of tree density and delta (Table 2). The values for the exponential model 
were, respectively, 30.9 and $53.1 \mathrm{~m}$. The joint estimation of delta and density of reproductive trees reduced the estimated tree density down to 1.6 trees/ha (normal model) and 1.3 trees/ha (exponential model). The differences for the error, calculated as a quadratic criterion by fitting the observed and expected pairwise $\Phi_{i j}$ values (Austerlitz and Smouse, 2002), were quite small among the models. The smallest error was obtained for the joint estimation in the exponential model.

\section{Discussion}

\section{Level of diversity}

With mean values of $A_{\mathrm{e}}=8.02$ and 9.16 , we observed relatively high values for the effective number of alleles. The seeds were sampled in three different parts of the Paracou sites, whereas the adults are mostly from one area (plot 16). This might explain the higher variation in the seed array. Our values were slightly higher than the mean value observed by Aldrich et al (1998) for $S$. globulifera in Costa Rica $\left(A_{\mathrm{e}}=7.02\right)$. Most other neotropical tree species had lower genetic diversity. In French Guiana, Latouche-Halle et al (2003) observed a mean value of $A_{\mathrm{e}}=3.23$ for the tree species Dicorynia guianensis, and in the same region Dutech et al (2002) found values between 1.69 and 2.08 for Voucapoua americana. Dick et al (2003) measured a mean value of $A_{\mathrm{e}}=3.50$ for Dinizia excelsa in Manaus (Brazil). Comparison among species should be carried out with caution because of the limited number of analysed loci and possible differences in mutation rate between di- and trinucleotide microsatellite loci. Nevertheless, results with different kind of gene markers (RAPDs, AFLPs and microsatellites) showed very similar ranking of tropical tree species diversity (Degen et al, 2003). The high level of diversity is probably linked to the large geographic distribution of $S$. globulifera, fitting the pattern seen for many tropical tree species using allozymes (Loveless, 1992).

\section{Heterozygosity}

For both the seeds $(F=0.12)$ and the adults $(F=0.16)$, we observed a significant excess of homozygotes compared to the expected Hardy-Weinberg proportions. This excess of homozygotes could be explained by the presence of null alleles, selfing and/or biparental inbreeding. Using information on the selfing rate (s), mean pollen dispersal (delta) and spatial genetic structure of adults, Fenster et al (2003) provided a formula to estimate an expected Fixation index $\left(F_{\text {exp }}\right)$ due to selfing and biparental inbreeding: $F_{\exp }=\left(2(1-s) F_{x}+s\right) /(2-s)$. Here $F_{x}$ is the biparental inbreeding coefficient (inbreeding coefficient of truly outcrossed progenies) calculated as kinship coefficient among mates within the radius of mean pollen dispersal. As has been shown by Hardy and Vekemans (1999), the kinship coefficient can be computed as approximately half of the Moran's I (see Figure 2). Using the above formula, we calculated for our population an expected value of $F_{\exp }=0.065$. Hence inbreeding would explain a part of the observed excess of homozygotes. There seems to be no strong selection against inbred progeny because the adult sample also had an excess of homozygotes. In other studies, a decrease of $F$-values has been reported with increasing age of the analysed ontogenetic stages (Morgante et al, 1993).

Another factor that might have contributed to the high values of $F$ in Paracou is the Wahlund effect. In French Guiana, two different ecotypes of S. globulifera have been observed. These ecotypes differ in leaf and seed size and have different environmental preferences (Loubry, 1994). About $90 \%$ of the observed trees in Paracou belong to a first type with relatively small leaves and seeds, which can be found in dry and swamp areas of the site. The remaining $10 \%$ of the trees belong to a second type with large leaves and seeds, which occurs preferentially in the swampy areas of the stand. If these types are not in reproductive contact and have different allele frequencies at the studied loci, this might be responsible for a part of the excess of homozygotes in Paracou and could explain the variation of $F$-values among loci. We measured the mean leaf size, of 60 adults in dry and swampy areas of plot 16 to test the presence of the Wahlund effect. These trees were included in the genetic study. After ranking the trees by leaf size, we classified them in two groups, one with big and one with small leaves. We did not find significant differences in allele frequencies among the two groups. Moreover, both groups still had a significant excess of homozygotes. Hence, we could not prove the impact of a Wahlund effect. Furthermore, Dick et al (2003), in context of their phylogeographic study, did not find any nucleotide differences at the sequenced internal transcribed spacer (ITS) between the two morphological types from Paracou. This also indicated no or only very little genetic difference between the two morphological types.

\section{Outcrossing rates}

The estimated multilocus outcrossing rate $t_{\mathrm{m}}$ was 0.920 . Our results fit well to the selfing rates between 0.098 and 0.261 observed for saplings by Aldrich and Hamrich (1998) in Costa Rica and confirm that S. globulifera is a predominantly outcrossing species. We observed a significant level of biparental inbreeding in Paracou $\left(t_{\mathrm{m}}-t_{\mathrm{s}}=0.156\right)$, which may be explained by limited pollen dispersal within the range of family structures. If there is a family structure, this can be evaluated by the analysis of spatial genetic structure of the adults. We found a significant positive spatial autocorrelation of genotypes for the adults up to $150 \mathrm{~m}$ (Figure 2). The high biparental inbreeding can be explained, if we compare the estimated range of mean pollen dispersal of $27-53 \mathrm{~m}$ with the scale of the observed spatial structure. It is quite clear that in Paracou most of the pollen flow is within a range of significant spatial structure. Another striking result was the high proportion of full-sibs $\left(r_{\mathrm{p}}=0.47\right)$. This fits together with the high level of biparental inbreeding. In Paracou, the trees are pollinated by a rather limited number of trees close to the mother tree. Stacy et al (1996) also observed for tropical tree species at Panama a strong correlation of paternity of crossed seeds, since pollinators visit neighbouring trees when trees are closely spaced. The population in Paracou has a high density of adult trees. Hence, we expected to have more different pollen donors represented in the offspring in Paracou. This contradictory result might be explained by unsynchronised flowering phenology in Paracou and by the composition and behaviour of the pollinators. As 
shown for the South American shrub species Helicteres brevispira, the behaviour of pollinating hummingbirds can change according to the density of flowering trees from promoting outcrossing by traplining to territorial pollination promoting selfing (Franceschinelli and Bawa, 2000). Hence, the trees in Paracou might be pollinated by rather territorial pollinators.

The TwoGener approach assumes homogeneous tree densities and independent pollen dispersal events following an isotropic distribution. Using Clark and Evan's index $(R)$, it could be shown that $S$. globulifera trees have a random spatial distribution in Paracou (Degen et al, 2001a). If pollinator behaviour causes strong preferential mating among particular adults, the mean dispersal distance (delta) should be underestimated. Similarly, variation in flowering intensities or phenology among adults causes delta to be underestimated when the density is fixed. Nevertheless, these effects should be minimised by the joint estimation.

\section{Effective pollen dispersal}

By use of the TwoGener approach we estimated, for the population in Paracou, mean pollen dispersal distances (delta, Table 2) between 27 and $53 \mathrm{~m}$. The values differed according to the dispersal model used (normal vs exponential model) and the estimation method (only delta estimation $v$ s joint estimation of delta and density). The joint estimation calculated an effective density of 1.6 reproductive trees/ha for the normal model and 1.3 reproductive trees/ha for the exponential model. This would imply that effectively about $13 \%$ of all trees $\geq 10 \mathrm{~cm}$ d.b.h. contributed to reproduction. Using the TwoGener approach Sork et al (2002) measured a mean pollen dispersal of $64.8 \mathrm{~m}$ for the wind pollinated Quercus lobata with a density of 1.19 trees/ha. With the same approach, Dick et al (2003) measured a mean pollen dispersal of $1509 \mathrm{~m}$ in a fragmented landscape and $212 \mathrm{~m}$ in undisturbed forests for the insect-pollinated tropical tree Dinizia excelsa with a density of 0.3 trees/ha. In comparison to these results, the pollen dispersal of $S$. globulifera is much shorter. This raises the possibility that birds, as the suspected main pollinators of S. globulifera, might be less efficient than bees or the wind. In general pollen dispersal seems to be negatively correlated with the tree density: the high tree density in Paracou led to short pollen dispersal. Such a correlation has been also found by Stacy et al (1996) and might result if pollinator behaviour fitted postulated optimal foraging strategy according to a cost-benefit function (Waddington and Holden, 1979).

In contrast to former studies with RAPDs (Degen et al, 2001a) we found a weak but significant positive spatial genetic autocorrelation up to $150 \mathrm{~m}$ (maximum of Moran's $I=0.041$ ) and a significant negative autocorrelation from 300 to $500 \mathrm{~m}$ (minimum of Moran's $I=-0.031$ ). This means close individuals are genetically more similar and pairs of individuals in a distance between 300 and $500 \mathrm{~m}$ are more different than expected for a random distribution. This is a pattern expected for clinal variation due to limited gene flow (Sokal and Oden, $1978 b)$. This range of Moran's I is small compared to other tree species studied at the same site. In comparison, Latouche-Halle et al (2003) observed for the rather aggregated tree species Dicorynia guianensis maximum values for Moran's I at microsatellite loci between 0.1 and 0.25 in the first distance class up to $50 \mathrm{~m}$. Hence, of the two species, $S$. globulifera has a weaker but larger spatial genetic structure. This can be explained by long distance seed dispersal (Hardy and Vekemans, 1999) and an overlapping of seed shadows. Seed dispersal is bat mediated in S. globulifera. This species probably has a more limited pollen dispersal than seed dispersal, in contrast to other species, due to its pollinator behaviour.

This paper is the first of a planned series on our results on S. globulifera. A second paper will describe the interannual variation of the mating system and gene flow in a Brazilian population with low density of $S$. globulifera. This population was subject to logging operations at the end of 2003. We will continue to study the mating system and gene flow of the species in the same stand for the next 2 years. This time series will enable us to compare the variation of mating system and gene flow under natural and disturbed conditions.

\section{Acknowledgements}

This study was financially supported by the European commission DG RESEARCH INCO-DEV, Project number: ICA4-CT-2001-10101 and a French grant from BRG (Bureau des Ressources Génétiques). We are thankful to Cirad-Forêt for giving us access to the experimental site Paracou and for providing data. We thank Christopher Dick, Frederick Austerlitz, Olivier Hardy, Stephen Cavers and two anonymous reviewer for critical comments and suggestions on the manuscript.

\section{References}

Aldrich PR, Hamrick JL (1998). Reproductive dominance of pasture trees in a fragmented tropical forest mosaic. Science 281: 103-105.

Aldrich PR, Hamrick JL, Chavarriaga P, Kochert G (1998). Microsatellite analysis of demographic genetic structure in fragmented populations of the tropical tree Symphonia globulifera. Mol Ecol 7: 933-944.

Andel TRv (2003). Floristic composition and diversity of three swamp forests in northwest Guyana. Plant Ecol 167: 293-317.

Austerlitz F, Dick CW, Dutech C, Klein E, Oddou-Muratoria S, Smouse PE et al (2004). Using genetic markers to estimate the pollen dispersal curve. Mol Ecol 13: 937-954.

Austerlitz F, Smouse PE (2001). Two-generation analysis of pollen flow across a landscape. II. Relation between $\phi_{\mathrm{ft}}$, pollen dispersal and interfemale distance. Genetics 157: 851-857.

Austerlitz F, Smouse PE (2002). Two-generation analysis of pollen flow across a landscape. IV. Estimating the dispersal parameter. Genetics 161: 355-363.

Bittrich V, Amaral MCE (1996). Pollination biology of Symphonia globulifera (Clusiaceae). Plant Syst Evol 200: 101-110.

Collevatti RG, Grattapaglia D, Hay JD (2001). High resolution microsatellite based analysis of the mating system allows the detection of significant biparental inbreeding in Caryocar brasiliense, an endangered tropical tree species. Heredity $\mathbf{8 6}$ : 60-67.

Degen B, Caron H, Bandou E, Maggia L, Chevallier MH, Leveau A et al (2001a). Fine-scale spatial genetic structure of eight tropical tree species as analysed by RAPDs. Heredity 87 : 497-507.

Degen B, Kanashiro M, Caron H, Kremer A, Thompson IS (2003). Etude génétiques menées en Amazonie: une colla- 
boration entre la Guyane française et le Brésil. Rev For Fr (in press).

Degen B, Petit R, Kremer A (2001b). SGS - Spatial genetic software: a computer program for analysis of spatial genetic structures of individuals and populations. J Hered 92: 447-448.

Dick C (2001). Genetic rescue of remnant tropical trees by an alien pollinator. Proc Roy Soc London Ser B 268: 2391-2397.

Dick CW, Etchelecu G, Austerlitz F (2003). Pollen dispersal of tropical trees (Dinizia excelsa: Fabaceae) by native insects and African honeybees in pristine and fragmented Amazonian rainforest. Mol Ecol 12: 753-764.

Doyle JJ, Doyle JL (1987). A rapid DNA isolation procedure for small quantities of fresh leaf tissue. Phythochem Bull 19: 11-15.

Dutech C, Seiter J, Petronelli P, Joly HI, Jarne P (2002). Evidence of low gene flow in a neotropical clustered tree species in two rainforest stands of French Guiana. Mol Ecol 11: 725-738.

Fenster CB, Vekemans X, Hardy OJ (2003). Quantifying gene flow from spatial genetic structure data in a metapopulation of Chamaecrista fasciculata (Leguminosae). Evolution 57: 995-1007.

Forget PM, Mercier F, Collinet F (1999). Spatial patterns of two rodent-dispersed rainforest trees, Carapa procera (Meliaceae) and Vouacapoua americana (Caesalpiniaceae) at Paracou, French Guiana. J Trop Ecol 15: 301-313.

Franceschinelli EV, Bawa KS (2000). The effect of ecological factors on the mating system of a South American shrub species (Helicteres brevispira). Heredity 84: 116-123.

Gill Jr GE, Fowler RT, Mori SA (1998). Pollination biology of Symphonia globulifera (Clusiaceae) in central French Guiana. Biotropica 30: 139-144.

Griffin CAM, Eckert CG (2003). Experimental analysis of biparental inbreeding in a self-fertilizing plant. Evolution 57: 1513-1519.

Hardy OJ, Vekemans X (1999). Isolation by distance in a continuous population: reconciliation between spatial autocorrelation analysis and population genetics models. Heredity 83: $145-154$.

Kanashiro M, Thompson IS, Yared JAG, Loveless MD, Coventry $P$, Martins-da-Silva RCV et al (2002). Improving conservation values of managed forests: the Dendrogene Project in the Brazilian Amazon. Unasylva 53: 25-33.

Latouche-Halle C, Ramboer A, Bandou E, Caron H, Kremer A (2003). Nuclear and chloroplast genetic structure indicate fine-scale spatial dynamics in a neotropical tree population. Heredity 91: 181-190.

Loubry D (1994). Déterminisme du comportement phénologique des arbres en forêt tropical humide de Guyane française ( $5^{\circ}$ lat. N.). PhD Thesis, University of Paris 6, Paris.

Loveless MD (1992). Isozyme variation in tropical trees: patterns of genetic organization. New Forests 6: 67-94.

Manly BFJ (1997). Randomization, Bootstrap and Monte Carlo Methods in Biology, Chapman \& Hall: London.

Maues MM (2001). Importance of the floral biology and pollinators on the sustainability of forest management. Acta Hortic 561: 81-85.
Morgante M, Vendramin GG, Rossi P, Olivieri AM (1993). Selection against inbreds in early life-cycle phases in Pinus leucodermis Ant. Heredity 70: 622-627.

Murawski DA, Hamrick JL (1991). The effect of the density of flowering individuals on the mating systems of nine tropical tree species. Heredity 67: 167-174.

Obayashi K, Tsumura Y, Ihara-Ujino T, Niiyama K, Tanouchi H, Suyama $Y$ et al (2002). Genetic diversity and outcrossing rate between undisturbed and selectively logged forests of Shorea curtisii (Dipterocarpaceae) using microsatellite DNA analysis. Int J Plant Sci 163: 151-158.

Pascarella JB (1992). Notes on flowering phenology, nectar robbing and pollination of Symphonia globulifera L.F. (Clusiaceae) in a lowland rain forest in Costa Rica. Brenesia 38 : 83-86.

Ritland K (2002). Extensions of models for the estimation of mating systems using $n$ independent loci. Heredity 88: 221-228.

Ritland K, Jain S (1981). A model for the estimation of outcrossing rate and gene frequencies using $n$ independent loci. Heredity 47: 35-52.

Schmitt L, Bariteau M (1988). Gestion de l'ecosysteme forestier guyanais: Etude de la croissance et de la regeneration naturelle: Dispositif de Paracou. Bois For Trop 220: 3-24.

Smouse PE, Dyer RJ, Westfall RD, Sork VL (2001). Twogeneration analysis of pollen flow across a landscape. I Male gamete heterogeneity among females. Evolution 55: 260-271.

Sokal RR, Oden NL (1978a). Spatial autocorrelation in biology. I Methodology. Biol J Linn Soc 10: 199-228.

Sokal RR, Oden NL (1978b). Spatial autocorrelation in biology. II. Some biological implications and four applications of evolutionary and ecological interest. Biol J Linn Soc 10: 229-249.

Sokal RR, Wartenberg DE (1983). A test of spatial autocorrelation analysis using an isolation-by-distance model. Genetics 105: 219-237.

Sork VL, Davis FW, Smouse PE, Apsit VJ, Dyer RJ, Fernandez$\mathrm{M} J \mathrm{~F}$ et al (2002). Pollen movement in declining populations of California Valley oak, Quercus lobata: where have all the fathers gone? Mol Ecol 11: 1657-1668.

Stacy EA, Hamrick JL, Nason JD, Hubbell SP, Foster RB, Condit R (1996). Pollen dispersal in low-density populations of three neotropical tree species. Am Nat 148: 275-298.

Streiff R, Labbe T, Bacilieri R, Steinkellner H, Glossl J, Kremer A (1998). Within-population genetic structure in Quercus robur L. and Quercus petraea (Matt.) Liebl. assessed with isozymes and microsatellites. Mol Ecol 7: 317-328.

Waddington KD, Holden LR (1979). Optimal foraging: on flower selection by bees. Am Nat 114: 179-197.

Weir BS (1996). Genetic Data Analysis II, Sinauer Associaties: Sunderland.

White GM, Boshier DH, Powell W (2002). Increased pollen flow counteracts fragmentation in a tropical dry forest: an example from Swietenia humilis Zuccarini. Proc Nat Acad Sci USA 99: 2038-2042. 